\title{
Species transformation and structure variation of fulvic acid during ozonation
}

\author{
LI Jing ${ }^{1,2}$, QU JiuHui ${ }^{1 \dagger}$, LIU HuiJuan ${ }^{1}$, LIU RuiPing ${ }^{1}$, ZHAO Xu $^{1} \&$ HOU YiNing ${ }^{1,2}$ \\ ${ }^{1}$ State Key Laboratory of Environmental Aquatic Chemistry, Research Center for Eco-Environmental Sciences, Chinese Academy of \\ Sciences, Beijing 100085, China \\ ${ }^{2}$ Graduate University of the Chinese Academy of Sciences, Beijing 100039, China
}

The species transformation and structure variation of fulvic acid (FA) during ozonation were investigated in this study. The molecular weight (MW) distribution, the species of intermediate products and the variation of polar functional groups were studied by ultrafiltration, gas chromatography/mass spectrometry (GC/MS) and titration analyses respectively. The average MW of FA decreased significantly during ozonation. The amount of polar functional groups (carboxylic and phenolic (ph-OH) groups) per unit DOC (mol/kg C) increased with increasing ozonation time. Furthermore, GC/MS experiments demonstrated the formation of polar species (e.g., hexadecanoic acid, benzoic acid and octadecanoic alcohol) and less-polar species (e.g., aliphatic hydrocarbons and butanedioic acid, bis(2-methylpropyl) ester). Electron spin resonance (ESR) measurements proved the presence of $\cdot \mathrm{OH}$ radicals in the ozonation system. Based on our experimental results, it appears that the oxidations by ozone molecule and $\cdot \mathrm{OH}$ radicals were responsible for the transformation of organics (FA and its oxidation products) during ozonation. These two oxidants showed significant influence on organics transformation and exhibited different mechanisms contributing to these processes.

fulvic acid, ozone, hydroxyl radicals, MW distribution, polar functional groups

\section{Introduction}

Ozone has been widely used in water treatment for its merits, such as high oxidation potential, fewer disinfection by-products (DBPs) formation and little secondary pollutant formation due to its self-decomposition ${ }^{[1]}$. In drinking water treatment, ozonation has been employed to extinguish algae cells, destruct microcystin and degrade the persistent organic pollutants (POPs) or endocrine disrupters (EDs) to enhance the safety of drinking water ${ }^{[2-4]}$. However, the intermediates (e. g., aldehydes, ketones and acids), formed from the reactions between ozone and compounds, probably enhance the biodegradability of drinking water and increase the DBPs formation during chlorination ${ }^{[5]}$. The objective of this study was to investigate the effect of ozonation on organic compounds. The property of degradation products was analyzed by ultrafiltration, GC/MS and titration analyses. FA, a main component of natural organic matters, was selected as the model organics in this study. Furthermore, the reaction path-way and mechanisms involved in these processes were discussed in detail.

\section{Materials and methods}

\subsection{Materials}

FA (commercial) was dissolved in deionized water, mixed for $24 \mathrm{~h}$ and filtered through $0.45 \mu \mathrm{m}$ membranes. Sodium bicarbonate, sulfate acid, sodium hydroxide, organic acids (hexadecanoic acid, tetradecanoic acid, benzoic acid and 1, 2-benzenedicarboxylic acid) and

Received July 4, 2007; accepted September 3, 2007 doi: 10.1007/s11426-008-0021-8

'Corresponding author (email: jhqu@rcees.ac.cn)

Supported by the National Natural Science Foundation of China (Grant No. 50538090) and the Funds for Creative Research Groups of China (Grant No. 50621804) 
octadecanoic alcohol were of analytical grade, and supplied by Beijing Chemical Reagents Company. The dichloromethane $\left(\mathrm{CH}_{2} \mathrm{Cl}_{2}\right.$, HPLC grade), potassium indigo trisulfonate $\left(\mathrm{C}_{16} \mathrm{H}_{7} \mathrm{~N}_{2} \mathrm{O}_{11} \mathrm{~S}_{3} \mathrm{~K}_{3}\right)$, derivative reagent $(\mathrm{N}$, O-bis (trimethylsilyl) trifluoro acetamide) (BSTFA) and spin trap reagent (5,5-dimethyl-1-pyrroline-N-oxide) (DMPO, analytical grade) were obtained in Aldrich Chemical Company.

\subsection{Experimental}

(1) Ultrafiltration experiments. Prior to ultrafiltration, all water samples were adjusted to the same ionic strength of $4.76 \mathrm{mmol} / \mathrm{L}$ and same $\mathrm{pH}$ at $8.2 \pm 0.2$ by adding sodium bicarbonate. Filtration experiments were performed on regenerated cellulose membranes with molecular weight cutoffs (MWCOs) of $5 \times 10^{3}, 1 \times 10^{4}$, $3 \times 10^{4}$ and $1 \times 10^{5}$, and conducted in a stirred cell (Model 8200 , Amicon Corp., Beverly, MA).

(2) Ozonation experiments. Ozonation was performed with a semi-batch equipment, which was composed of an oxygen generator (Beijing Boyikang Lab Instrument Co., Ltd.), an ozone generator (Ozonizer series OS-N, MISUBISHI), a magnetic mixer and a glass reactor (3 L) (Figure 1). The temperature was maintained at $(20.0 \pm$ $3.0)^{\circ} \mathrm{C}$ by an air-conditioner. The $1.8 \mathrm{mg} / \mathrm{min}$ gas ozone was continuously introduced into the reactor at a flow rate of $150 \mathrm{~mL} / \mathrm{min}$. During ozonation, samples were withdrawn from the reactor for analysis at certain time intervals.

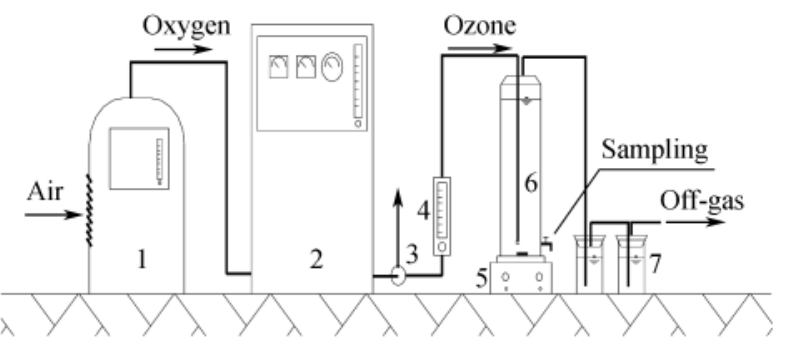

Figure 1 Schematic of the experimental set-up. (1) Oxygen generator; (2) ozone generator; (3) three-way valve; (4) flowmeter; (5) magnetic mixture; (6) reactor; (7) absorption bottle.

\subsection{Analysis methods}

The $\mathrm{pH}$ values of solutions were measured on an Orion 720 APLUS Benchtop meter (Thermo Orion Co., USA).

The DOC concentrations in water samples were measured by using a multi N/C 3000 TOC analyzer (Analytik Jena AG, Germany) after being filtered through a $0.45 \mu \mathrm{m}$ membrane.

The less polar and polar organic compounds in the solution were pre-treated according to an USEPA method $625^{[6]}$. The compounds were extracted with dichloromethane by liquid/liquid extraction. The less polar organic compounds were analyzed by using a GC/MS (Agilent 6890N Series $/ 5973$ MSD, USA). For the analysis of polar organic compounds, they were derived by BSTFA. The derived samples were then analyzed by using the GC/MS.

ESR spectra were obtained by using an ESP $300 \mathrm{E}$ electron paramagnetic resonance spectrometer (Bruker Co., Germany).

The amount of carboxylic and ph-OH groups in compounds was determined on an automatic potentiometric titrator (Metrohm 716 Co., Switzerland) ${ }^{[7]}$.

\section{Results and discussion}

\subsection{The MW distribution of organics during ozona- tion}

Figure 2 shows the MW distribution of FA and its ozonation products. The MW of the major organic compounds present in the sample is in the range of $(1-$ $30) \times 10^{4}$, which contributed about $45 \%$ DOC. As expected, ozonation reduced the amount of high MW organic compounds $\left(>3 \times 10^{4}\right)$ and increased the portion of low MW compounds. In detail, after 50 min of ozonation, the distribution ratios of DOC in high MW fractions $\left(>3 \times 10^{4}\right)$ decreased from $35.4 \%$ to $19.6 \%$, whereas that in low MW fractions $\left(<1 \times 10^{4}\right)$ increased from

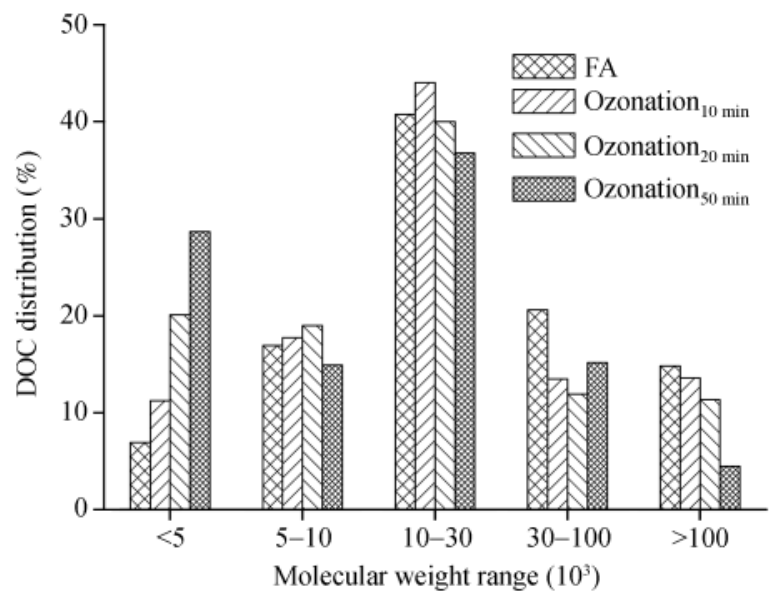

Figure 2 The MW distribution of organics during ozonation. Initial DOC: $(3.0 \pm 0.2) \mathrm{mg} / \mathrm{L}, \mathrm{pH}: 8.2 \pm 0.2,(20.0 \pm 3)^{\circ} \mathrm{C}, 1.8 \mathrm{mg} / \mathrm{min}$ ozone gas concentration, inlet flow rate: $150 \mathrm{~mL} / \mathrm{min}$. 
$23.8 \%$ to $43.5 \%$. These results demonstrate that ozonation significantly changed the structure and MW distribution of FA.

Chiang et al. reported that during ozonation natural organic matter (NOM) could be decomposed into lower MW counterparts, and the average MW of organic compounds decreased ${ }^{[8]}$. On the other hand, Jason ${ }^{[9]}$ found that humic substance (HS) was degraded via an outside-in trimming mechanism. Ozone molecules (or hydroxyl radicals) attacked the periphery of HS molecules, and small fragments of low MW were cleaved. These intermediates with low MW were mineralized or transformed into other organic compounds in further ozonation. The slow decrease in MW of FA during ozonation (Figure 2) indicates that the destruction of FA follows the outside-in trimming mechanism.

\subsection{The evolution of polar functional groups of or- ganics during ozonation}

To investigate the changes in properties of organic compounds during ozonation, the relative contents of polar functional groups (mainly as carboxylic and ph-OH groups) (mol/kg C) of intermediates were determined. The polar functional group concentration of oxidation products $(\mathrm{mol} / \mathrm{L})$ was normalized by its DOC concentration $(\mathrm{kg} / \mathrm{L})$. The contents of carboxylic and ph-OH groups in FA were found to be $7.25 \mathrm{~mol} / \mathrm{kg} \mathrm{C}$ and $1.93 \mathrm{~mol} / \mathrm{kg} \mathrm{C}$ respectively, implying that $\mathrm{FA}$ employed in this study had more carboxylic groups and less ph-OH groups than humic acid ${ }^{[10]}$. The content of carboxylic and ph-OH groups increased with increasing ozonation time (Figure 3). This indicates that ozonation

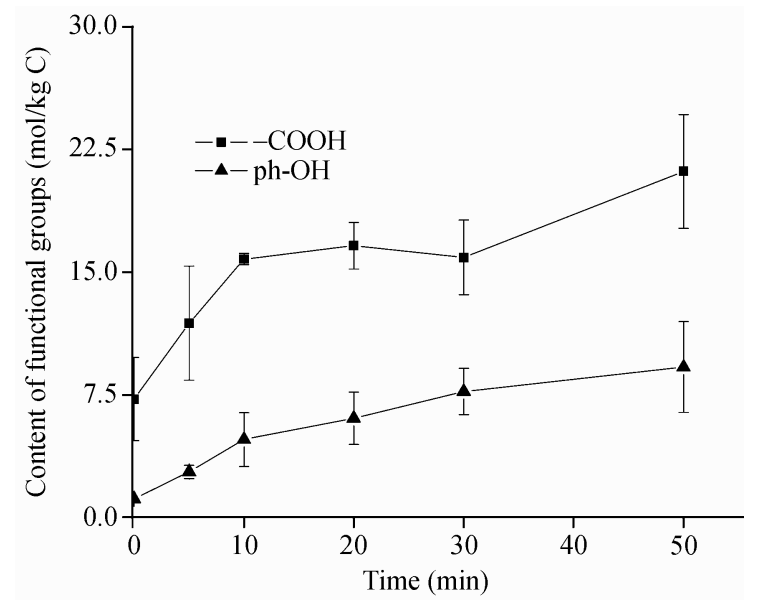

Figure 3 The variation of relative amount of $-\mathrm{COOH}$, ph-OH groups in organics during ozonation. Initial DOC: $(3.0 \pm 0.2) \mathrm{mg} / \mathrm{L}, \mathrm{pH}: 8.2 \pm 0.2$, $(20.0 \pm 3)^{\circ} \mathrm{C}, 1.8 \mathrm{mg} / \mathrm{min}$ ozone gas concentration, inlet flow rate: 150 $\mathrm{mL} / \mathrm{min}$. destructs the structure of FA, forming more $-\mathrm{COOH}$ and ph-OH groups and changing the properties of organic matter during ozonation.

\subsection{Intermediate products detected by GC/MS}

In order to investigate the possible pathways involved in the reactions between ozone and $\mathrm{FA}$, the intermediate products were determined through GC/MS analysis. It should be pointed out that only organic compounds with $\mathrm{MW}<500$ were detected due to the limitation of GC/MS. Additionally, only the relatively stable intermediates could be extracted from the reaction system because the active, unstable intermediates will not last when exposed to ozone and hydroxyl radicals with such high oxidation potentials $(2.07 \mathrm{~V} \text { and } 2.80 \mathrm{~V})^{[11]}$. So the organic compounds detected by GC/MS were a portion of intermediates relatively stable and having low MW.

(1) The formation of the polar intermediates during ozonation. The relative concentration of polar organics derived from ozonation process is shown in Figure 4. Apparently, the concentration of oxidation intermediates, such as aromatic acids, aliphatic acids and alcohols, increased from $0 \mathrm{~min}$ to $10 \mathrm{~min}$ and then decreased subsequently. Interestingly, the concentrations of these organic compounds remained relatively unchanged after 20 min of ozonation.

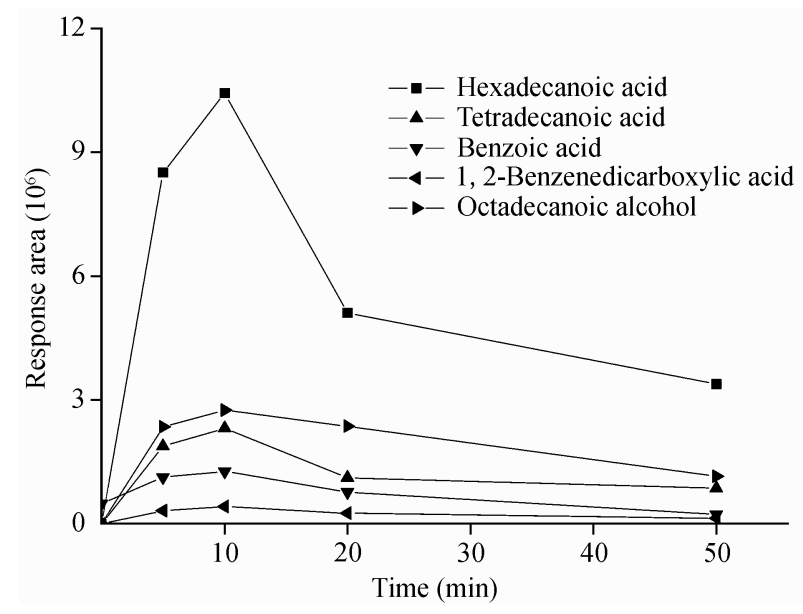

Figure 4 The variation of concentration of polar organics during ozonation. Initial DOC: $(3.0 \pm 0.2) \mathrm{mg} / \mathrm{L}, \mathrm{pH}: 8.2 \pm 0.2,(20.0 \pm 3)^{\circ} \mathrm{C}, 1.8 \mathrm{mg} / \mathrm{min}$ ozone gas concentration, inlet flow rate: $150 \mathrm{~mL} / \mathrm{min}$.

Previous studies $[12,13]$ reported that the presence of electron-withdrawing groups such as $-\mathrm{COOH}$ changed the electron density of aromatic structure $\mathrm{C}=\mathrm{C}$ or $\mathrm{C}-\mathrm{C}$ structure, resulting in the inhibition of the oxidation by ozone molecule. The oxidation of these organic acids 
was believed to be caused by $\cdot \mathrm{OH}$ radicals. In addition, the formation of octadecanoic alcohol, with a maximum concentration appearing at $10 \mathrm{~min}$ of ozonation, was observed (Figure 4). The formation of alcohols might be attributed to the reaction between $\cdot \mathrm{OH}$ radicals and $\mathrm{C}-\mathrm{C}$ structure via hydrogen-abstraction mechanism ${ }^{[14,15]}$. These results indicated that the presence of $\cdot \mathrm{OH}$ radicals affected the transformation of intermediate products during ozonation.

(2) The formation of less-polar intermediates during ozonation. Apart from the presence of organic acids and alcohols, the less-polar intermediates were also observed during ozonation. The qualitative analysis of the less polar intermediates $(\mathrm{MW}<500)$ was also performed (Table 1).

As shown in Table 1, the species of less-polar intermediates changed significantly during ozonation. Before ozonation, almost no less-polar species were detected in FA sample. After $10 \mathrm{~min}$ of ozonation, more less-polar organic species (e. g., aliphatic hydrocarbon, aromatic compounds, ketones and esters) were detected. Moreover, these intermediates detected were mainly aliphatic hydrocarbon, aromatic compounds after $50 \mathrm{~min}$ of ozonation.

As stated in previous sections, prior to ozonation, few less-polar organic compounds were detected by GC/MS in FA sample. After ozonation, the structural and chemical properties of FA were changed. Specifically, organic species with high MW were broken into low MW compounds such as aldehydes, ketones, hydrocarbon and esters by ozone molecules (or $\cdot \mathrm{OH}$ radicals). After 50 min of ozonation, organic compounds with high reactivity (e. g., ketones and esters ) were mineralized into $\mathrm{CO}_{2}$ and $\mathrm{H}_{2} \mathrm{O}$ or oxidized forming small organic acids (e. g., oxalic acid) by $\mathrm{O}_{3}$ (or $\cdot \mathrm{OH}$ radicals) ${ }^{[16]}$. In fact, the products, formed after $50 \mathrm{~min}$ of ozonation, had higher saturated hydrocarbon content than that formed in the initial 10 min of reaction (Table 1), indicating that the saturated hydrocarbons were the main final products.
Notably, the hydrocarbons with polyaromatic rings (e. g., naphthalene, anthracene, phenanthrene or their derivates) were also detected during ozonation. According to Kramer ${ }^{[17]}$ that HS had highly condensed rings within its complex molecular structure, it could be concluded that ozonation destructed the highly condensed rings into the compounds with less condensed structures, such as naphthaline, anthracene, phenanthrene or their derivates (Table 1).

\subsection{The proposed reaction pathway in the reaction between $F A$ and ozone}

The formation of DMPO-OH was detected by the ESR experiments, indicating the presence of $\cdot \mathrm{OH}$ radicals in the ozonation system (Figure 5). In addition, the intensity of DMPO-OH signal in ESR spectra in ozonated FA was stronger than that in ozonated pure solution, implying that FA promotes the formation of $\cdot \mathrm{OH}$ radicals during ozonation. Overall, it is concluded that the transformation of organics during ozonation could be attributed to direct molecular ozone oxidation and indirect $\cdot \mathrm{OH}$ radicals oxidation $^{[18]}$.
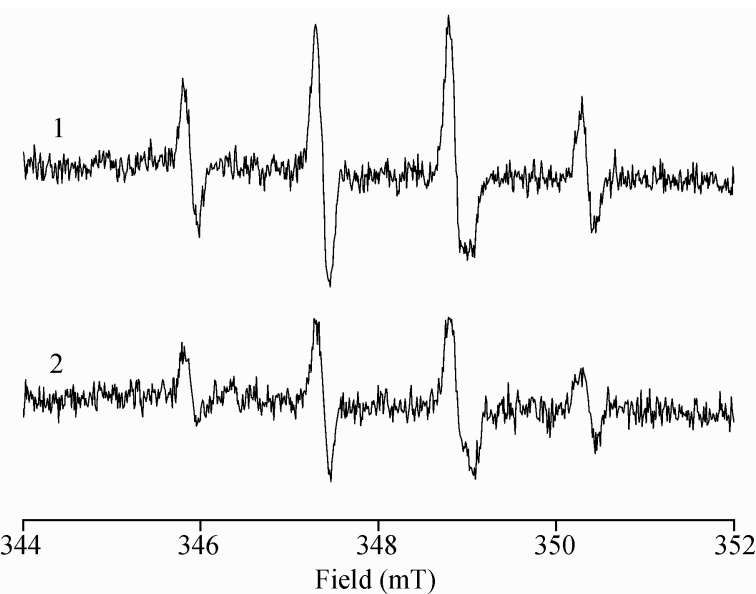

Figure 5 The ESR spectra of the ozonation system (1) in ozonated FA and (2) in ozonated pure solution. Initial DOC: $(3.0 \pm 0.2) \mathrm{mg} / \mathrm{L}, \mathrm{pH}$ $8.2 \pm 0.2,(20.0 \pm 3)^{\circ} \mathrm{C}$, the concentration of dissolved ozone in solution: 10 $\mathrm{mg} / \mathrm{L}$.

Table 1 The half-polar organic detected by GC/MS

\begin{tabular}{cccc}
\hline Time $(\mathrm{min})$ & 0 & 10 & 50 \\
\hline $\begin{array}{c}\text { Aromatic hydrocarbon } \\
\text { Ketones }\end{array}$ & N.D. & p-Xylene & Anthracene,1,4-dimethyl Benzene, 2-ethyl Phenanthrene, \\
N.D. & 3-Heptanone Acetophenone Cyclohexanone & N.D. \\
$\begin{array}{c}\text { Aliphatic } \\
\text { hydrocarbon }\end{array}$ & N.D. & 1,1,4-Dioxane, 2,5-dimethyl & Undecane, Pentadecane, Tridecane, Dimethyl-Hexadecane, \\
Esters & N.D. & $\begin{array}{c}\text { Eicosane, Nonadecane } \\
\text { Docosane, Pentacosane, 4,6,8-trimethyl Azulene }\end{array}$ & N.D. \\
\hline
\end{tabular}

N.D.: not detected. Initial DOC: $(3.0 \pm 0.2) \mathrm{mg} / \mathrm{L}, \mathrm{pH} 8.2 \pm 0.2,(20.0 \pm 3)^{\circ} \mathrm{C}, 1.8 \mathrm{mg} / \mathrm{min}$ ozone gas concentration, inlet flow rate: $150 \mathrm{~mL} / \mathrm{min}$. 
Reckhow $^{[19]}$ reported that ozone molecules slowly and selectively attacked electron-donating structures (e. g., aromatic structure, olefins and amine groups). The formation of ketones and esters mainly resulted from the reaction between $\mathrm{O}_{3}$ and $\mathrm{C}=\mathrm{C}$ structures. These intermediates could be transformed into organic acids via the reaction with $\mathrm{O}_{3}$ in the further oxidation (eq. 1). In our experiments, the formation of ketones and esters in the initial 10 min of ozonation and the subsequent disappearance of these products in the further oxidation (50 min of ozonation) verified these reaction pathways (Table 1).

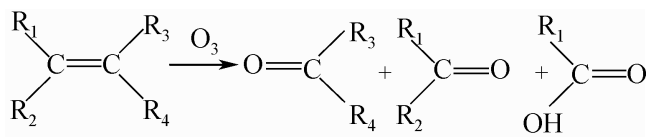

Compared with the ozone molecule, $\cdot \mathrm{OH}$ radicals possesses higher oxidation potential and reacts with organics more rapidly and unselectively. The reaction rate of $\cdot \mathrm{OH}$ radicals has been reported to be about $10^{8}-10^{10}$ $\mathrm{L} \cdot \mathrm{mol}^{-1} \cdot \mathrm{s}^{-1[13]}$, which is higher than that of ozone molecules $\left(1.0-10^{3} \mathrm{~L} \cdot \mathrm{mol}^{-1} \cdot \mathrm{s}^{-1}\right)^{[12]}$. $\cdot \mathrm{OH}$ radicals mainly reacts with organics via hydrogen- abstraction or $\cdot \mathrm{OH}$ radicals addition. In detail, $\cdot \mathrm{OH}$ radicals can react with aromatic $\mathrm{C}=\mathrm{C}$ structure in $\mathrm{FA}$ to form phenolic compounds and ethers via addition reactions. In contrast, its reaction with $\mathrm{C}-\mathrm{C}$ structure produces alcohols and epoxides $^{[14,15]}$. These intermediates can be mineralized or transformed into small organic acids by ozone molecules and $\cdot \mathrm{OH}$ radicals during ozonation ${ }^{[20]}$. The possible pathways involved in these processes are shown in eqs. $(2)-(9)^{[14,15,20]}$. In this study, results of GC/MS and titration analysis verified the formation of alcohols and phenolic compounds, and proved the reaction pathways and mechanism in ozonation.

1 Singer P C. Control of disinfection by-products in drinking water. J Environ Eng, 1994, 120: 727-743

2 Wang Z, Liu J. Drinking Water Treatment of Micro-Pollution Raw Water (in Chinese). Beijing: China Architecture and Building Press, 1999. $188-189$

3 Rositano J, Newcombe G, Nicholson B, Sztajnbok P. Ozonation of NOM and algal toxins in four treated waters. Water Research, 2001, 35(1): $23-32$

4 Li H, Qu J. Ozonation of the trace endocrine disruption (DBP) in drinking water. Acta Scientiae Circumstantiae (in Chinese), 2003, 23(5): $570-574$

5 Rook J J. Formation of haloforms during chlorination of natural wa-

$$
\begin{gathered}
\mathrm{RH}+\mathrm{HO} \cdot \mathrm{R} \cdot+\mathrm{H}_{2} \mathrm{O} \\
\mathrm{R} \cdot+\mathrm{O}_{2} \rightarrow \mathrm{ROO} \cdot \\
\mathrm{ROO} \cdot \mathrm{RH} \rightarrow \mathrm{ROOH}+\mathrm{R} \cdot \\
\mathrm{ROH} \rightarrow \mathrm{RH}+\mathrm{ROH}+\mathrm{R} \cdot
\end{gathered}
$$

\section{Conclusion}

(1) Ozonation could destruct the structure and decrease the MW of FA under the weak basic condition.

(2) Ozonation resulted in the formation of more polar organic compounds, as is evidenced by the increase in the relative content of polar functional groups (carboxylic and ph-OH groups) as ozonation proceeds.

(3) The formation of aliphatic acids, aromatic acids and alcohols can be ascribed to the ozonation of FA. Furthermore, the abundance of these polar organics increased in the initial period of ozonation and then decreased after a long time of ozonation.

(4) Both direct oxidation by ozone molecules and indirect oxidation by $\cdot \mathrm{OH}$ radicals were identified to be at work in the species transformation and structure variation of oxidation products. $\cdot \mathrm{OH}$ radicals reacted with the bonds in organics via hydrogen-abstraction and $\cdot \mathrm{OH}$ addition mechanisms, while ozone molecules attacked aromatic $\mathrm{C}=\mathrm{C}$ structure. The two different mechanisms resulted in the formation of different intermediate products.

ters. Water Treat Exam, 1974, 23: 234-245

6 EPA (1984) Method 625-Base/Neutrals and Acids. 49, No. 209. US Environmental Protection Agency

7 Barak P, Chen Y. Equvialent radii of humic macromolecules from acid-base titration. Soil Sci, 1992, 154(3): 184-195

8 Chiang P C, Chang E E, Liang C H. NOM characteristics and treatabilities of ozonation process. Chemosphere, 2002, 46(6): 929-936

9 Jason R H S, Zwijnenburg A, van der Meer W G J, Wessling M. Outside-in trimming of humic substance during ozonation in a membrane contactor. Environ Sci Technol, 2006, 40(20): 6460-6465

10 Li L. Molecular structure characterizations of different humic acid fractions and their effects on the sorption of phenanthrene. State Key 
Laboratory of Organic Geochemistry, Guangzhou Institute of Geochemistry, Chinese Academy of Sciences. Dissertation for the degree of Doctor, 2003

11 Zhao W, Shi H, Wang D. Ozonation of cationic red X-GRL in aqueous solution: Degradation and mechanism. Chemosphere, 2004, 57(9): $1189-1199$

12 Hoigné J, Bader H. Rate constants of reactions of ozone with organic and inorganic compounds in water. II. Dissociation organic compounds. Water Res, 1983, 17(2): 185-194

13 Haag W R, Yao C C D. Rate constants for reactions of hydroxyl radicals with several drinking water contaminants. Environ Sci Technol, 1992, 26(5): 1005-1013

14 Emanuel N M. The Oxidation of Hydrocarbons in the Liquid Phase, 1st ed, Pergamon: New York, 1965

15 Walling C. In Active Oxygen in Chemistry; Foote C S, Valentine J S, Greenberg A, Liebman J F, Eds.; Blackie Academic \& Professional: Glasgow, 1995. 44-45

16 Kosaka K, Yamada H, Shishida K, Echigo S, Minear R A, Tsuno H,
Matsui S. Evaluation of the treatment performance of a multistage ozone/hydrogen peroxide process by decomposition by-products. Water Res, 2001, 35(15): 3587-3594

17 Kramer R W, Kujawinski E B, Zang X, Green-Church K B, Jones R B, Freitas M A, Hatcher P G. Studies of the structureof humic substances by electrospray ionization coupled to a quadrupole-time of flight (QQ-TOF) mass spectrometer. Special Publication - Royal Society of Chemistry 273 (Humic Substances), 2001, 273: 95-107

18 Hoigné J, Bader $\mathrm{H}$. The role of hydroxyl radical reactions in ozonation processes in aqueous solutions. Water Res, 1976, 10(5): 377-386

19 Reckhow D A. Control of disinfection by-product formation using ozone. In: Formation and control of disinfection by-products in drinking water; Singer P C, Eds.; Denver CO: American Water Works Association; 1999. 179-204

20 Chen R, Pignatello J J. Role of quinone intermediates as electron shuttles in fenton and photoassisted fenton oxidations of aromatic compounds. Environ Sci Technol, 1997, 31(8): 2399-2406 